\title{
The Performance Evaluation of Low Heat Rejection Diesel Engine with Alternate Fuels and Pollution Control-A Critical Review
}

\author{
Pawan Kumar Pulijala, Mohammed Umair Mohiuddin, Sunkanapally Vijay and Anvesh Theeradala \\ Mechanical Engineering Department, Chaitanya Bharathi Institute of Technology, Gandipet, Hyderabad 500 075, (Telangana), India
}

Received 05 Feb 2018, Accepted 08 April 2018, Available online 12 April 2018, Vol.8, No.2 (March/April 2018)

\begin{abstract}
The usage of alternate fuels has been a priority ever since the depletion of the conventional fuels. During the recent times the concept of using biodiesel as fuel has been predominant due to its ability to be used in the same engine as conventional fuels. The source of biodiesels are mainly non edible oils such as Jatropha and Pongamia. This paper reviews the properties of the alternate fuels when used in the compression-ignition engine. These alternate fuels used are vegetable oils and alcohols. The review compares the key properties of diesel to the alternate fuels used. The properties such as such as brake thermal efficiency, volumetric efficiency, exhaust gas temperature and smoke levels are compared with the values obtained from the usage of conventional diesel fuel in a low heat rejection engine (L.H.R) engine. apart from the properties there is also a need for the check of pollutants emitted during the processes, oxides of nitrogen from diesel fuel and aldehydes from the alternate fuels.
\end{abstract}

Keywords: Alternate fuels, Conventional fuels etc.

\section{Introduction}

The ${ }^{1}$ civilization of a particular country has come to be measured on the basis of the number of automotive vehicles being used by the public of the country. The tremendous rate at which population explosion is taking place imposes expansion of the cities to larger areas, and common man is forced these days to travel long distances even for their routine works. This in turn is causing an increase in vehicle population at an alarmed rate thus bringing in pressure on government to spend huge foreign currencies for importing crude petroleum to meet the fuel need of the automotive vehicles.

The factors leading to the development of LHR engine are that in a diesel engine only $30 \%$ of the total energy is useful and the search for alternate fuels such as vegetable oils and their blends has been a major priority. The several methods adopted for developing an LHR diesel engine are- (i) using ceramic coatings on piston, liner and cylinder head (ii) creating air gap in piston (iii) components with low thermal conductivity materials like superni, mild steel etc., (iv) injection pressure is increased for bio diesel fuel.

The consumption of conventional fuels like diesel is very high in transport, industrial and agricultural sectors, leading to fossil fuel crisis, besides

*Corresponding author's ORCID ID: 0000-0001-9159-8877 DOI: https://doi.org/10.14741/ijcet/v.8.2.24 environmental pollution. Initially alcohols were considered as better alternative for diesel fuels as they can be produced from cheaper and renewable resources. But the drawbacks are low cetane number and high latent heat of vapourization, call for hot combustion chamber, which is provided by Low Heat Rejection (LHR) diesel engine. Alcohol is injected through variable jet carburetor during suction stroke and diesel at the end of compression stroke through injector. Alcohol as fuel reduces smoke and NOx levels, fuel cracking reactions are eliminated as the combustion of alcohol is predominantly a process of hydroxylation, and the ratio of carbon to hydrogen atoms is less. The major pollutant with alcohols is aldehydes which are carcinogenic in nature. The nonedible vegetable oils like Jatropha and Pongamia oils in crude and esterified forms can also be used as a future fuels in CI engines. When these oils are used the commonly expected pollutants are smoke black smoke and NOx levels. This is mainly caused due to the low volatility and high viscosity associated with these oils, thus causing serious health hazards. The effects of esterified vegetable oils and preheating are also needed to be studied.

The present paper outlines the performance evaluation of LHR engines tested on various alternate fuels and pollution levels are determined and compared to $\mathrm{CE}$ with pure diesel operation with an objective to replace the use of diesel fuel in CE. 


\section{Methodology}

The low heat rejection diesel engine consists of a two part piston in which the crown made of low thermal conductivity material, superni90 (an alloy of iron and nickel) screwed to the aluminium body of the piston, providing a $3 \mathrm{~mm}$ gap in between the body and crown of the piston. It is screwed in such a manner so that the air gap acts as an insulator with lower thermal conductivity at $500 \mathrm{C}$. The thermal conductivity of superni90 and air are 20.92 and $0.057 \mathrm{~W} / \mathrm{m}-\mathrm{K}$ respectively.

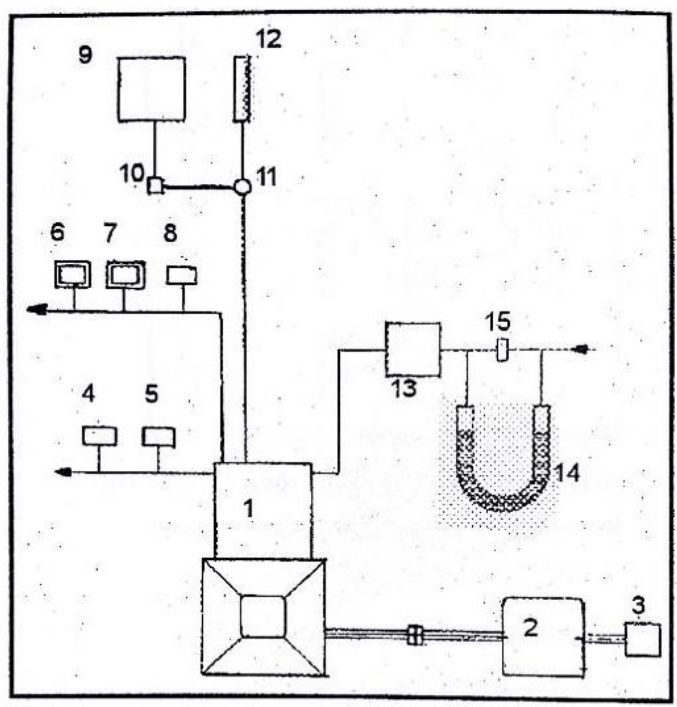

1. Engine, 2. Electrical dynamometer, 3. Load box, 4. Outlet jacket water temperatur indicator, 5 . Out late jacket water flow meter, 6. Exhaust gas temperature indicator, 7. AVL Smoke meter, 8. Netel Chromatograph NOx analyzer, 9. Fuel tank, 10. Heater with thermometer arrangement, 11. Three-way valve, 12. Burette, 13. Air-box, 14. U-tube water manometer and 15 . Orifice meter.

\section{Fig.1 Experimental set-up}

Alcohol operation: The experimental investigation is carried out on a single cylinder vertical water cooled medium speed 3.68KW diesel engine at a rated speed of 1500rpm and coupled to an electrical dynamometer. The reccommended injection timing and injection pressure of the engine by the manufacturer are $27^{\circ}$ bTDC and 190 bar respectively. The experiments were carried out with conventional engine and LHR engine. The details of the assemblies of the insulated piston and insulated liner are shown in the fig.1. the experimental setups for alcohol diesel mixtures is shown in fig2.the experiment is carried out with the help pf Rheostat box connected to an electrical dynamometer. The alcohol is inhaled through variable jet carburettor along with air during the suction stroke of the engine at different percentages of the diesel consumption by mass basis at full load operation of the engine. The consumption of alcohol (ethanol and methanol) and diesel were carried out separately by means of fuel measuring devices fitted to alcohol tank and diesel tank. The aair consumption awsaa obtained using air box, orifice meter and water tube manometer assembly. Exhaust gag temperature was measured by employing iron and iron-constantan thermocouple fitted to temperature indicator. The oxides of nitrogen (NOx) are recorded using Netel Chromatograph NOx analyzer. Black smoke in hartridge smoke unit was noted using AVL smoke meter. The aldehyde emissions were measured by bubbling the exhaust through 3 stage 2,4-Dinitrophenyl Hydrazine solution in hydrochloric acid and extracting the hydrogens formed into chloroform. The extract was analyzed using high performance liquid chromatograph. The pollution levels of NOx and black smoke were recorded for different proportions of ethanol diesel and methanol diesel mixtures in addition to pure diesel operation on both conventional and LHR versions of engine. The aldehyde emissions were noted at maximum induction of alcohol for conventional and LHR engines in addition to pure diesel operation at peak load operation of the engine.

\section{Results and discussions}

\section{Based on experimentation on alcohol as fuel}

The maximum induction of alcohol is 35\% with conventional engine and 50\% with LHR engine.graph 1 shows the comparative data of formaldehyde and acetaldehyde emissions with CE and LHR engine at different percentages of alcohol induction.

The over-leaning of fuel injected during the ignition delay period is the significant source of aldehyde emissions,especially under conditions where ignition delay is long.locally over-rich mixture due to which no ignition or flame propagation takes place is also one source of formation of formaldehyde.LHR engine has reduced aldehydes emissions marginally when compared to conventional engine with pure diesel operation.The reduction of aldehydes is due to high exhaust gas temperatures with LHR engine,which leads to oxidization of aldehydes.Formaldehyde emissions are higher with methanol induction, while acetaldehyde emissions are observed to be higher with the ethanol induction in both versions of the engine.LHR engine marginally reduced aldehyde emissions at peak load operation with pure diesel;Aldehyde emissions have increased with the increase of alcohol induction in both configurations of the engine;Aldehyde emissions have decreased with alcohol operation with LHR engine. 
Table 1:The comparative data on the variation of pollution levels at peak load with different percentages of alcohol induction for the conventional and LHR engines at an injection timing of $27^{\circ} \mathrm{bTDC}$ and at an injection pressure of 190 bars

\begin{tabular}{|c|c|c|c|c|c|c|c|c|}
\hline $\begin{array}{c}\text { Percentage of } \\
\text { alcohol }\end{array}$ & \multicolumn{2}{|c|}{$\begin{array}{c}\text { Smoke levels (hsu) } \\
\text { engine version }\end{array}$} & \multicolumn{2}{c|}{$\begin{array}{c}\text { Nox levels (ppm) engine } \\
\text { version }\end{array}$} & \multicolumn{2}{c|}{$\begin{array}{c}\text { Formaldehyde concentration (\%) } \\
\text { engine version }\end{array}$} & $\begin{array}{c}\text { Acetaldehyde concentration } \\
\text { (\%) engine version }\end{array}$ \\
\hline & C.E. & L.H.R & C.E. & L.H.R & C.E. & L.H.R & C.E. & L.H.R \\
\hline $\mathbf{0}$ & 48 & 58 & 850 & 1300 & 6 & 7 & 5 & 6 \\
\hline $\mathbf{3 5 M E}$ & 38 & 42 & 425 & 800 & 23.3 & 21.12 & 13 & 11.22 \\
\hline $\mathbf{3 5 E T}$ & 35 & 45 & 465 & 855 & 12.64 & 10.15 & 22.5 & 20.12 \\
\hline $\mathbf{4 0 M E}$ & - & 36 & - & 750 & - & - & - & - \\
\hline $\mathbf{4 0 E T}$ & - & 36 & - & 820 & - & - & - & - \\
\hline $\mathbf{5 0 M E}$ & - & 24 & - & 565 & 37.2 & 26.6 & 21.06 & 15.08 \\
\hline $\mathbf{5 0 E T}$ & - & 28 & - & 740 & 19.6 & 14.15 & 35.32 & 25.65 \\
\hline
\end{tabular}

Table 2:Data of smoke levels with different versions of the engine with different test fuels at various injection Pressures

\begin{tabular}{|c|c|c|c|c|c|c|}
\hline \multirow{2}{*}{ Test fuel } & \multicolumn{5}{|c|}{ Smoke level (hsu) } \\
\cline { 2 - 6 } & \multicolumn{5}{|c|}{ CE } & \multicolumn{3}{c|}{ LHR } \\
\cline { 2 - 6 } & \multicolumn{4}{|c|}{ Injection Pressure (bar) } & \multicolumn{3}{|c|}{ Injection Pressure (bar) } \\
\hline & 190 & 230 & 270 & 190 & 230 & 270 \\
\hline D & 48 & 38 & 34 & 63 & 55 & 45 \\
\hline EJO & 63 & 58 & 53 & 45 & 40 & 35 \\
\hline EPO & 65 & 60 & 55 & 50 & 45 & 40 \\
\hline
\end{tabular}

Table 3:Data of oxides of nitrogen(NOx) at peak load operation with different versions of the engine with different test fuels at various injection pressures

\begin{tabular}{|c|c|c|c|c|c|c|}
\hline \multirow{5}{*}{ Test fuel } & \multicolumn{6}{|c|}{ Nox Levels (ppm) } \\
\hline & \multicolumn{6}{|c|}{ Engine Version } \\
\hline & \multicolumn{3}{|c|}{$\mathrm{CE}$} & \multicolumn{3}{|c|}{ LHR } \\
\hline & \multicolumn{3}{|c|}{ Injection Pressure (bar) } & \multicolumn{3}{|c|}{ Injection Pressure (bar) } \\
\hline & 190 & 230 & 270 & 190 & 230 & 270 \\
\hline D & 850 & 890 & 930 & 1400 & 1380 & 1360 \\
\hline EJO & 820 & 830 & 870 & 1250 & 1180 & 1140 \\
\hline EPO & 850 & 980 & 920 & 1275 & 1205 & 1165 \\
\hline
\end{tabular}

\section{Jatropa and pongamia oil based bio-diesel}

Pure diesesl operation on LHR engines increased smoke levels because of fuel cracking.LHR engine marginally decreased smoke levels due to efficient combustion and less amount of fuel accumulation on the hot combustion chamber walls of the LHR engines at different operating conditions of the vegetable oil compred to the conventional engine.Pongamia oil based bio-diesel produced more smoke levels when compared to jatropha oil based bio-diesel in both CE and LHR engine due to higher value of $\mathrm{C} / \mathrm{H}$ ratio and density and lower value of volumetric efficiency for pongamia oil based bio-diesel.Temperature and availabilityof oxygen are responsible factors for formation of NOx levels.Increase of combustion temperatures with the faster combustion and improved heat release rates in the LHR engine cause higher NOx levels.Increase of injection pressure decreased pollution levels with test fuels in both versions of the engine.
Pure diesel operation on LHR engines increased smoke levels because of fuel cracking. Pongamia oil based biodiesel produced more smoke levels when compared to jatropha oil based bio-diesel in both versions of the engine due to higher value of $\mathrm{C} / \mathrm{H}$ ratio and density and lower value of volumetric efficiency for pongamia oil based bio-diesel. However, rapid increase of smoke levels was observed at the peak load operation in both versions of thee engine at different operating conditions of the vegetable oil, compared to pure diesel operation on conventional engine due to higher magnitude of $\mathrm{C} / \mathrm{H}$ when compared to pure diesel. The increase in smoke levels is also due to decrease of air fuel ratios and volumetric efficiency waste fried vegetable oil compared with pure diesel operation. In LHR engine.

With pure diesel operation, NOx levels are higher in LHR engine when compared to conventional engine due to increase of temperatures in the hot environment created in LHR engines. NOx levels are lower in CE with vegetable oil operation in comparison $\mathrm{CE}$ with pure diesel operation due to lower heat release rate because 
of high duration of combustion causing lower gas temperatures. Increase of combustion temperatures with the faster combustion and improved heat released rates in the LHR engine cause higher NOx levels.CPO produced higher NOx levels when compared to EJO in both versions of engine because of higher calorific value of CPO leading to produce higher gas temperature causing more NOx levels. Increased IP decreased NOx levels in LHR engine while they increased in CE due to decrease of gas temperatures.

NOx levels are lower in the CE while they are higher in the LHR engine at different operating conditions of the crude vegetable oils at the peak load when compared to diesel operation. This is ue to lower heat release rate because of high duration of combustion causing lower gas temperatures with the vegetable oil operation on CE, which reduced NOx levels. Increase of combustion temperatures with faster combustion and improved heat release rates in the LHR engine cause higher NOx levels. However preheating of Vegetable oils increased NOx levels in the CE and reduced the same in LHR engines. This is due to increased mass burning rates with which combustion temperatures increase in the NOx emissions in the conventional engine and decrease of combustion temperatures in the LHR engine with the improvement in the air fuel ratios leading to decrease NOx levels in the LHR engine.

\section{Vegetable oil as fuel}

The conventional engine with waste fried oil showed the deterioration in the performance when compared to the pure diesel operation. However L.H.R version of the engine showed the improved performance compared to C.E, with waste fried oil. High cylinder temperatures helped in better evaporation and faster combustion of the fuel injected into the combustion chamber. Reduction of ignition delay of the vegetable oil in the hot environment of the L.H.R engine improved heat release rates and efficient energy utilization. Hot combustion chamber of LHR engine has reduced ignition delay and more energy is transferred to the piston as the work is done on the piston approaching at top dead center. BSEC is higher with vegetable oil operation with conventional engine in comparison with pure diesel operation. The L.H.R engine has a recorded a lower value of EGT when compared to the conventional engine with vegetable oil operation.

Table 4:The variation of peak BTE with injection timing and injection pressure in the CE and LHR engine at different operating conditions of various alternate fuels

\begin{tabular}{|c|c|c|c|c|c|c|c|}
\hline & & \multicolumn{3}{|c|}{ Conventional Engine } & \multicolumn{3}{c|}{ L.H.R Engine } \\
\hline S.No. & Fuel & $\operatorname{IP}(190)$ & $\mathrm{IP}(230)$ & $\mathrm{IP}(270)$ & $\mathrm{IP}(190)$ & $\mathrm{IP}(230)$ & $\mathrm{IP}(270)$ \\
\hline $\mathbf{1}$ & DF & 28 & 29 & 30 & 29 & 30 & 30.5 \\
\hline $\mathbf{2}$ & CPO & 25 & 26 & 27 & 28.5 & 29.5 & 30 \\
\hline $\mathbf{3}$ & Vegetable Oil & 27 & 28 & 29 & 29 & 30 & 32 \\
\hline
\end{tabular}

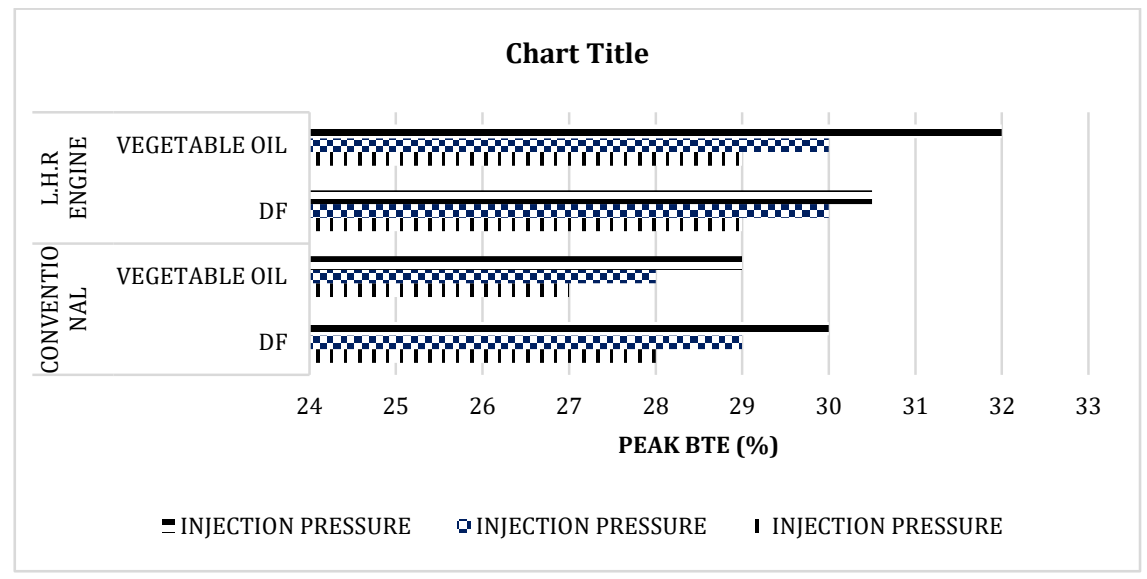

Fig.2. Bar charts showing the variation of peak brake thermal efficiency with different versions of the engine at normal temperature of waste fried vegetable oil and at different injection pressures

Table 5:The variation of peak EGT with injection timing and injection pressure in the CE and LHR engine at different operating conditions of various alternate fuels

\begin{tabular}{|c|c|c|c|c|c|c|c|}
\hline & & \multicolumn{3}{|c|}{ Conventional Engine } & \multicolumn{3}{c|}{ L.H.R Engine } \\
\hline S.No.. & FUEL & IP(190) & IP(230) & IP(270) & IP(190) & IP(230) & IP(270) \\
\hline $\mathbf{1}$ & DF & 425 & 410 & 395 & 460 & 450 & 440 \\
\hline $\mathbf{2}$ & CPO & 525 & 500 & 490 & 470 & 450 & 430 \\
\hline $\mathbf{3}$ & Vegetable Oil & 497 & 485 & 469 & 467 & 455 & 438 \\
\hline
\end{tabular}


Chart Title

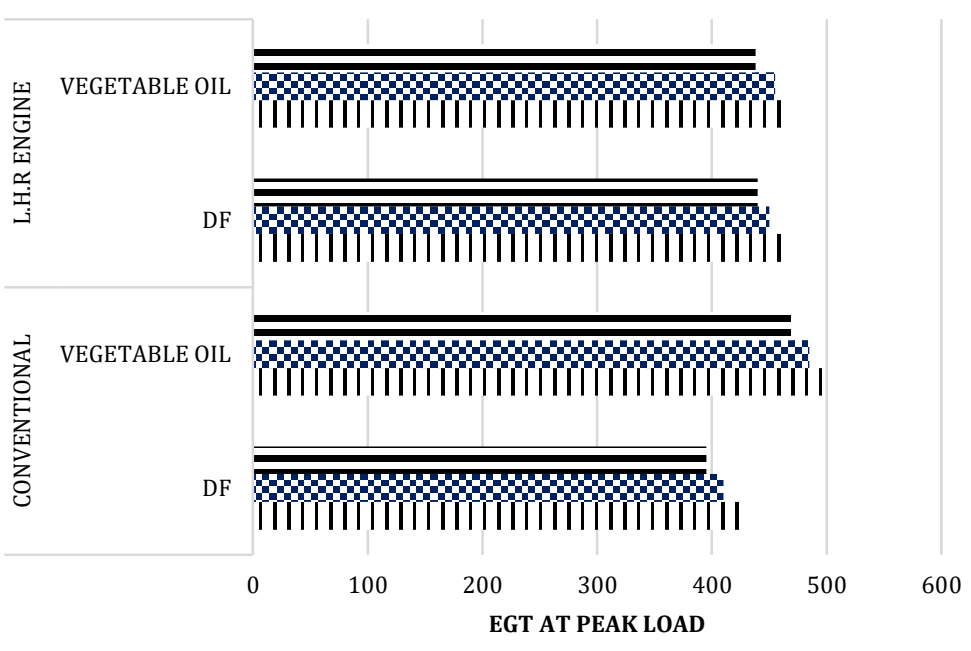

=INJECTION PRESSURE $\quad \boldsymbol{x I N J E C T I O N ~ P R E S S U R E ~ I ~ I N J E C T I O N ~ P R E S S U R E ~}$

Fig.3. Bar charts showing the variation of exhaust gas temperature(EGT) at peak load with different versions of the engine at normal temperature of waste fried vegetable oil and at different injection pressures

Table 6:The variation of volumetric efficiency with injection timing and injection pressure in the CE and LHR engine at different operating conditions of various alternate fuels

\begin{tabular}{|c|c|c|c|c|c|c|c|}
\hline & & \multicolumn{3}{|c|}{ Conventional Engine } & \multicolumn{3}{c|}{ L.H.R Engine } \\
\hline S.No. & Fuel & IP(190) & IP(230) & IP(270) & IP(190) & IP(230) & IP(270) \\
\hline $\mathbf{1}$ & DF & 85 & 86 & 87 & 78 & 80 & 82 \\
\hline $\mathbf{2}$ & CPO & 78.5 & 79.5 & 80.5 & 75.5 & 76.5 & 77.5 \\
\hline $\mathbf{3}$ & VEGETABLE OIL & 76 & 78 & 80 & 74 & 76 & 78 \\
\hline
\end{tabular}

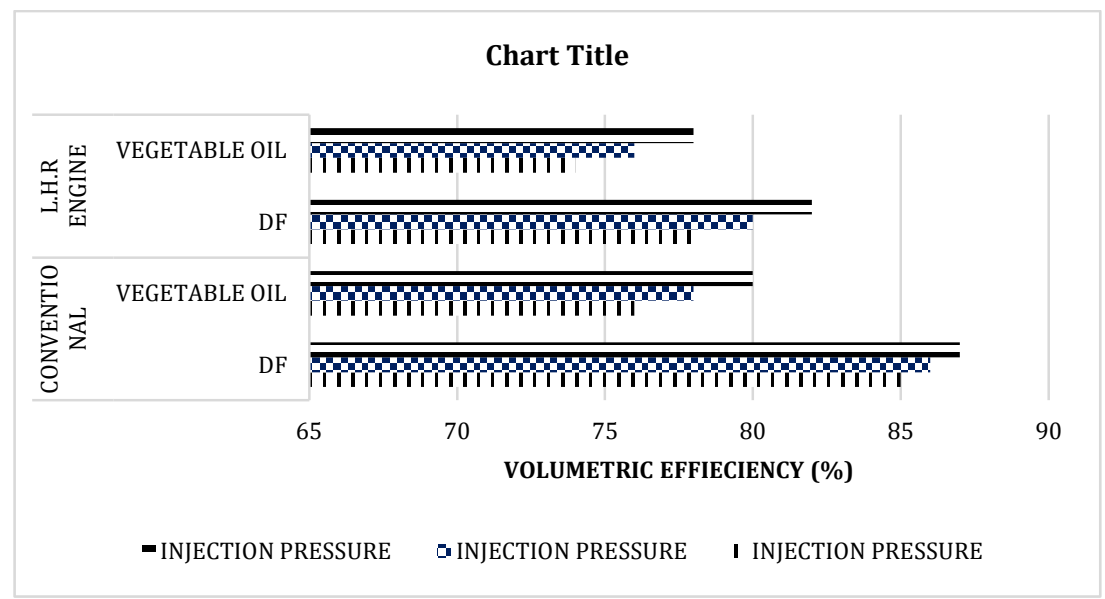

Fig.4. Bar charts showing the variation of volumetric efficiency at peak load with different versions of the engine at normal temperature of waste fried vegetable oil and at different injection pressures.

Table 7:The variation of smoke levels with injection timing and injection pressure in the CE and LHR engine at different operating conditions of various alternate fuels

\begin{tabular}{|c|c|c|c|c|c|c|c|}
\hline & & \multicolumn{3}{|c|}{ Conventional engine } & \multicolumn{3}{c|}{ L.H.R engine } \\
\hline S.No. & Fuel & IP(190) & IP(230) & IP(270) & IP(190) & IP(230) & IP(270) \\
\hline $\mathbf{1}$ & DF & 48 & 38 & 34 & 55 & 50 & 45 \\
\hline $\mathbf{2}$ & CPO & 70 & 65 & 63 & 55 & 45 & 40 \\
\hline $\mathbf{3}$ & Vegetable Oil & 77 & 73 & 68 & 65 & 60 & 55 \\
\hline
\end{tabular}




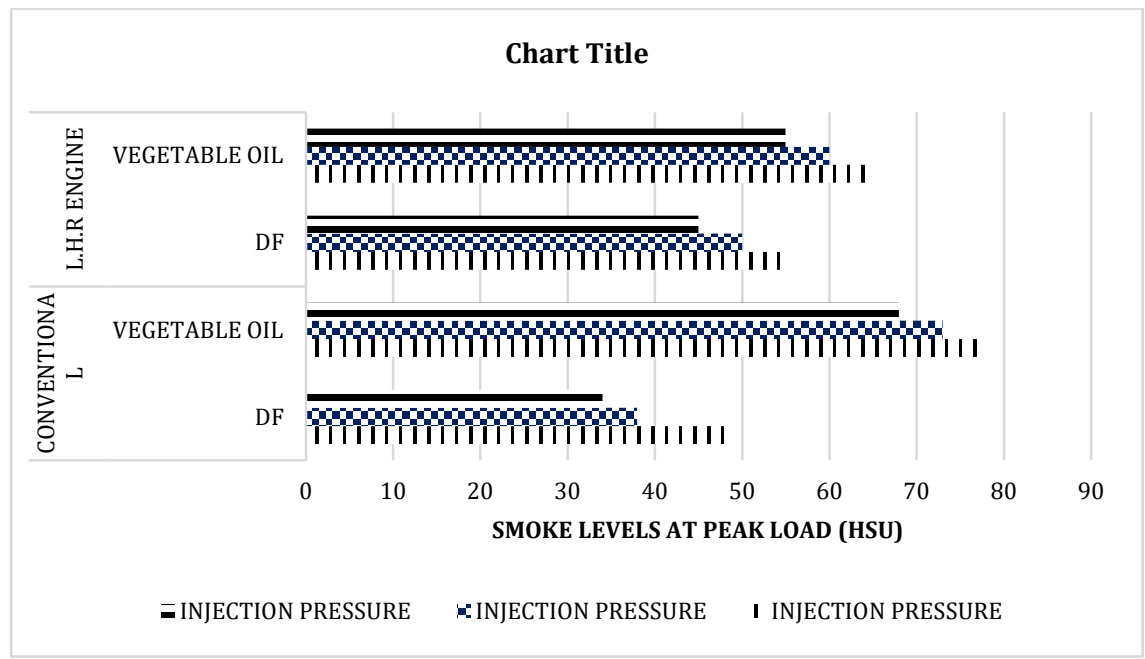

Fig.5. Bar charts showing the variation of smoke levels at peak load with different versions of the engine at normal temperature of waste fried vegetable oil and at different injection pressures

Drastic increase of smoke levels was observed at peak load operation in the both versions of the engine at different operating conditions of the vegetable oil, compared to pure diesel operation on conventional engine. This is due to the higher magnitude of the ratio $\mathrm{C} / \mathrm{H}$, when compared to the pure diesel. The increase of smoke levels is also due to decrease of air/fuel ratios and volumetric efficiency with waste fried vegetable oil compared with pure diesel operations. However, the L.H.R engine marginally reduces the smoke levels due to efficient combustion and less amount of fuel accumulation on the hot combustion chamber walls of L.H.R engine at different operating conditions of the vegetable oil compared to the conventional engine. NOx levels at peak load are lower in conventional engine while they are higher in the LHR engine at different operating conditions of the crude vegetable oils at the peak load when compared to diesel operation. This is due to lower heat release rate because of high duration of combustion causing lower gas temperatures with the vegetable oil operation on conventional engine which reduced to NOx levels.

Table 8:The variation of NOx levels with injection timing and injection pressure in the CE and LHR engine at different operating conditions of various alternate fuels

\begin{tabular}{|c|c|c|c|c|c|c|c|}
\hline & & \multicolumn{3}{|c|}{ Conventional engine } & \multicolumn{3}{c|}{ L.H.R Engine } \\
\hline S.No. & Fuel & $\operatorname{IP}(190)$ & $\mathrm{IP}(230)$ & $\mathrm{IP}(270)$ & $\mathrm{IP}(190)$ & $\mathrm{IP}(230)$ & $\mathrm{IP}(270)$ \\
\hline $\mathbf{1}$ & $\mathrm{DF}$ & 850 & 810 & 770 & 1300 & 1280 & 1260 \\
\hline $\mathbf{2}$ & CPO & 740 & 700 & 660 & 1265 & 1235 & 1200 \\
\hline $\mathbf{3}$ & Vegetable Oil & 720 & 740 & 760 & 1280 & 1230 & 1190 \\
\hline
\end{tabular}

NOX LEVELS AT DIFFERENT IP'S

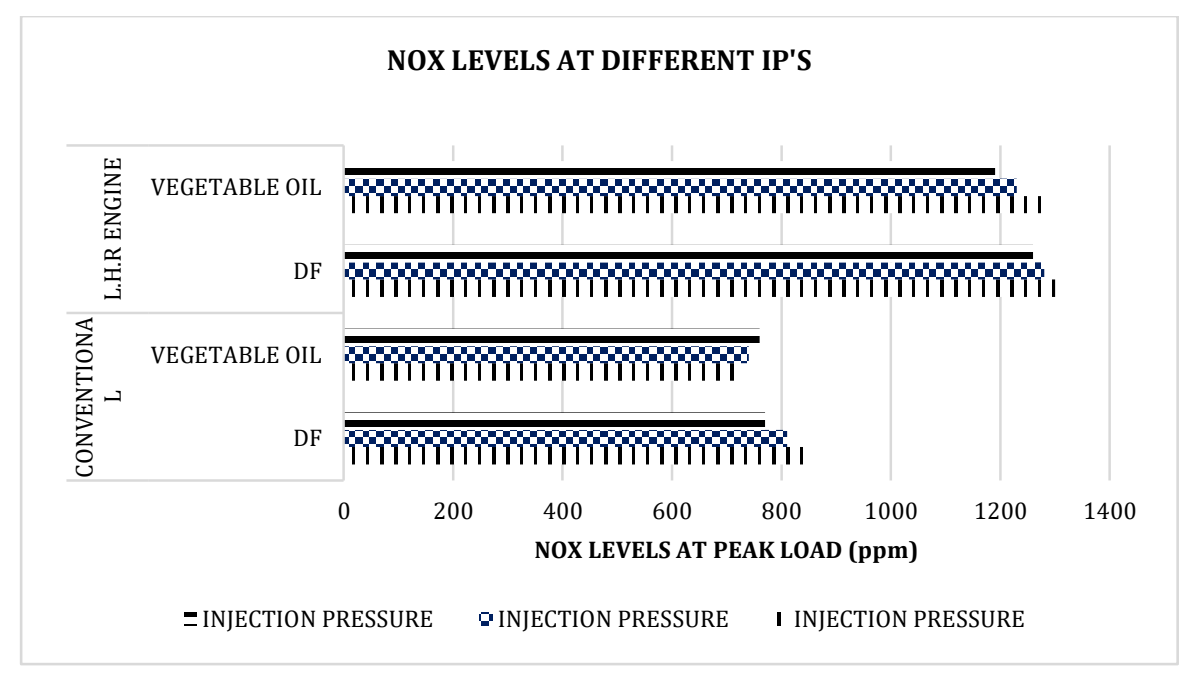

Fig.6. Bar charts showing the variation of NOx levels at peak load with different versions of the engine at normal temperature of waste fried vegetable oil and at different injection pressures 


\section{Conclusions}

Operation of vegetable oil at $27^{\circ} \mathrm{bTDC}$ on C.E showed the deterioration in the performance, while L.H.R engine showed an improved performance when compared to pure diesel operation on C.E. Increase of injection pressure increased efficiency and decreased pollution levels in both versions of the engine.

It is concluded that ethanol and methanol induction decreased the smoke levels and increased the aldehyde emissions when compared with pure diesel operation. On the other hand, L.H.R engine decreases the smoke and aldehyde emissions when compared to C.E.

Jatropha oil based bio-diesel decreased pollution levels when compared to pongamia oil based bio-diesel in both versions of engine. Increase of injection pressure decreased pollution levels with test fuels in both versions of the engine.

\section{References}

Ch. Kesava Reddy, M.V.S Murali Krishna, P.V.K Murthy and T. Ratna Reddy Performance evaluation of a low grade L.H.R diesel engine with crude Pongamia oil.
M.V.S Murali Krishna, T.K.K Reddy, V.V.R Seshagiri Rao and R.P. Chowdary comparative studies of pollution levels of high grade insulated engine with Jatropha oil and pongamia oil based Bio-Diesel.

M.V.S Murali Krishna Investigations on low heat rejection diesel engine with alternate fuels. Ph.D Thesis, J.N.T University, Hyderabad. 2004

M.V.S Murali Krishna, R.P. Chowdary, A. Satish Chandra, V. Shiva Krishna and $\mathrm{CH}$. Raju Performance evaluation of L.H.R Diesel engine with blends of diesel and wate fried vegetable oil.

M.V.S Murali Krishna, C.M. Vara Prasad Studies of exhaust emissions in L.H.R diesel engine with alternate fuels.

Annapuma Devi, N., Mohan Kumar, C., Rama Naidu, N. And Narasimha, M.2006. Production and evaluation of biodiesel from Sunflower and nigerseed oil with performance studies on a diesel engine. Proc. International Congress on Renewable Energy-2006, Hyderabad. 478-484.

Rama Mohan, K. 1995. Performance evaluation of an air gap insulated piston engine. Ph.D . Thesis, Kakatiya University.

Parker, DA. And Dennison, G. M. 1987. The development of an air gap insulated piston, SAE Paper No.870652.

Murali Krishna, M.V.S 2004. Investigations on low heat rejection diesel engine with alternate fuels. Ph.D Thesis, J.N.T.University, Hyderabad.

Rehman, A. and Singhai, K.C.1995. Vegetable oils as alternate fuels for diesel engine. Proc.IV Asian-Pacific International Symposium on Combustion and Energy Utilization, Hong Kong.924-928. 